\title{
Gestalt Principles in Destination Logos and Their Influence on People's Recognition and Intention to Visit a Country
}

\author{
Lulu Rodriguez, Iowa State University, USA \\ Ruby Lynn Asoro, Iowa State University, USA \\ Suman Lee, Iowa State University, USA \\ Sela Sar, Iowa State University, USA
}

\begin{abstract}
This study sought to determine the influence of gestalt principles exhibited in destination logos on audience's the extent to which they recognize the country based on its tourism icon and intention to visit a country. A total of 154 logos were collected from the websites of 116 countries, and were rated based on the degree to which six gestalt principles (similarity, proximity, continuity, figure-ground, closure, assimilation) were present in each. Based on the scores, the logos were classified as having high, medium and low gestalt attributes. Two representative logos for each level were selected. An online survey of undergraduate students was conducted to determine the influence of these gestalt traits on recognition and people's intention to visit the country being promoted. The results reveal that high- and mediumgestalt logos elicited greater recognition to visit compared to their low-gestalt counterparts. High-gestalt logos also produced stronger intention to visit than the symbols with mediumand low-gestalt attributes.
\end{abstract}

Keywords: gestalt, logo design, tourism logos, destination logos 


\section{Introduction and Problem Statement}

Last December, Vietnam's Ministry of Culture, Sports and Tourism inaugurated the latest version of the country's symbol and slogan for its four-year tourism promotion program (2012-2015). The new logo, shown below, features a five-petal lotus with the tagline, "Vietnam-Timeless charm." The symbol replaced the lotus bud and the slogan "VietnamHidden charm" the country has been using for the past four years. According to the designers, the lotus symbolizes the beauty and vitality of the number five in Oriental philosophy. The bright green color depicts island, sea, and the ecology, Vietnam's major tourist attractions. Yellow stands for culture and history, violet is for adventure, and pink represents Vietnamese hospitality (Vietnam National Administration of Tourism, 2012).

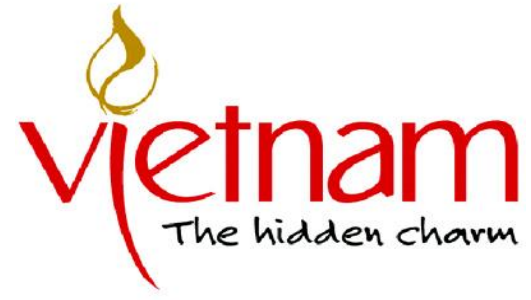

Vietnam's “old” 2008-2011 tourism logo

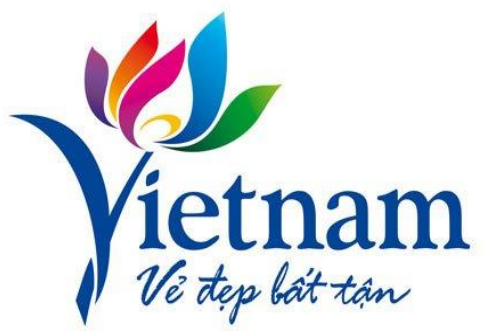

The new logo for the 2012-2015 program

The new logo, however, was greeted with dismay (Travel Blackboard, 2012). Government officials gripe that the revised icon "does not help tourists imagine the beauty of Vietnam." Tourism directors worry that the symbol needs to be accompanied by a strong action plan. Designers fret that too many colors will tax those in charge of quality control. Linguists lament the slogan's incorrect grammar. Travel firms were surprised, unaware that their tourism logo had been changed. The general public found the logo sophisticated but unintelligible, requiring a great deal of explanation and remedial lessons in Vietnamese symbology to comprehend (Ha, 2012).

The reactions of different sectors to Vietnam's most recent destination logo showcase the difficulty of encapsulating the totality of a place in a cogent symbol, and the recognition that logos are critical components of efforts to establish destination brand identity. This rigorous process begins by surveying the broad competition to pinpoint what gives the logo brand distinction and culminates with massive promotion efforts to maximize exposure (Wanderlust 
Travel and Destination Marketing, 2009).

There is no debate that a distinctive design can imbue a brand with a unique presence and expression. While a destination logo is only one component of a brand, it functions as a "visual ambassador." Designers say the right logo creates desire; it has a point of view. It represents a body of core ideas, yet rarely can it perform this task literally; the best logos imply meaning through representation and metaphor (e.g., Wheller, 2006).

Why do nations invest in destination logos? There is no doubt that the rapid growth in international tourism has motivated governments to promote their countries as prime tourist destinations. The United Nations World Tourism Organization (UNWTO) reports that over 900 million tourists crossed international borders for their holidays, generating revenues of US $\$ 856$ billion in 2007 alone (Bowman, 2010). Although there was a decline in these figures in 2009 perhaps as a consequence of the worldwide recession, global tourism "recovered strongly" in 2010 with an overall increase of $6.7 \%$, adding 935 million tourists mainly from the emerging economies of Asia, the Middle East, and the Americas (Goodman, 2011). Despite the worldwide economic slump, the UNWTO forecasts a continuous growth trend in international tourism, projecting 1.8 billion international tourists by 2030 and an average of 43 million new tourists every year from 2010 to 2030 (UNWTO, 2011). North East Asia, the Organization predicts, will be the most popular destination in the world, likely to attract $16 \%$ of total arrivals (UNWTO, 2011).

This projected pace of growth has understandably prompted governments to position their countries as prime tourist destinations. In doing so, they have turned to branding techniques to establish an image and to differentiate their country on the global market. One of the ways to attain a competitive edge is by deploying a memorable destination logo (Jaffe and Nebenzahl, 2001; Kleppe and Mossberg, 2006). These logos aim to communicate distinction or a unique identity (Harish, 2010). They have been known to elicit desired notions and emotions, influence behavior (Rafaeli et al., 2008), and speed up recognition (Berry, 1989; Morrow, 1992). According to Rafaeli et al. (2008), a country logo may reflect special or historical events or it may present the ethos of its citizens. A strong country brand has been found to equate to substantial tourist arrivals (Fetscherin, 2010). Harish (2010) found that 
prospective visitors and investors rely significantly on the destination's image in making their decisions.

Because of this, efforts are expended to arrive at the "right" visual identity. Among other attributes, this visual identity, encapsulated in a logo, must be congruent with the message, and must be crafted for high impact considering minimal or fast-paced exposure. In the design of such logos, gestalt principles are particularly useful because such principles offer a visual frame of reference designers can use as a reliable psychological basis for the spatial organization of graphic information. In effect, gestalt perceptual factors offer guidelines as to how the eye organizes visual experiences. Indeed, how people evaluate a logo has been found to affect their evaluations of the organizations the logos represent (Aronczyk, 2008; Henderson and Cote, 1998).

Although there are numerous studies on logo design characteristics (e.g., Fang and Mowen, 2005; Zhang et al., 2006), few have examined the deployment of a wide range of gestalt principles in logo design (Chang et al., 2001; Cao, 2003). Often, discussions in marketing literature are limited to various rules of thumb propagated in the trade press that have been neither tested empirically nor integrated to form a comprehensive set of guidelines.

This study aims to expand the literature on the effect of design on consumer evaluation of logos by assessing the gestalt characteristics of country logos for tourism and their influence on people's recognition of and intention to visit the country these logos represent. The results are expected to offer insights in the development of visual assets on which countries spend enormous time and money to promote (Hutton, 1997; Lentschner, 2001; Henderson et al., 2003).

\section{Literature Review and Theoretical Perspective}

Within the context of tourism, destination logos can facilitate marketing activities to establish brand image and identity, particularly relevant before the actual visit takes place. Because travelers can choose from among thousands of destinations to visit, effective destination branding provides visitors with an assurance of quality experiences, reduces visitor search costs, and offers a way for destinations to establish a unique selling proposition (Blain, Levy \& Ritchie, 2005). 
Although there is no definitive definition of a country brand, Papp-Váry (2010) generally defines it as something that combines visual communication and marketing techniques to promote a country. Country branding aims to "stimulate exports, attract tourists, investments, and immigration, and create positive international perceptions and attitudes" (Fetscherin, 2010, p. 468). A traditional dimension of country branding is a "destination image," which involves "not only the perceptions of individual destination attributes but also the holistic impression made by the destination" (Echtner and Brent Ritchie, 1991, p. 8). Destination image has been shown to be a significant determinant of visitors' choice of places to see (Lee et al., 2002). In the severe competition for tourists and their spending dollars, destination branding strives to achieve seven broad objectives-image, recognition, differentiation, consistency, brand messages, emotional response, and expectations (Blain et al., 2005).

\section{Logo Outcomes}

Earlier studies have shown that some logos have been successful in eliciting positive emotions, conveying meaning, enhancing behavioral intentions, and raising recognition about a company or brand (van der Lans et al., 2009; Henderson et al., 2003). Rafaeli et al. (2008) found that symbols and corporate logos can lead people to do things they otherwise would not do, suggesting the logos' utility whenever trust and spontaneous compliance are needed. Henderson et al. (2003) laud the logos' portability, pointing out that they are "the most common element of the marketing mix that can be used in an unaltered form when going abroad" (p. 298).

Pimentel (1997) defined a logo as visual shorthand that carries desirable meanings and associations for products, services, and organizations. Logos communicate image, "cutting through clutter to gain attention, and speeding the recognition of a product or company" (Henderson and Cote, 1998, p. 15). Scholars generally agree that logos should be recognizable, familiar, elicit a consensual meaning, and create positive affective reaction (e.g., Cohen, 1986; Robertson, 1989).

As visual symbols, logos are supposed to be recognized more quickly than words (Edell \& Staelin, 1983). Designing easily recognizable logos is critical because they should survive fast-exposure environments; people are generally exposed to logos only for brief periods of time. Henderson and Cote (1998) suggest that logo recognition happens in two levels: first, 
audiences should recognize the logo correctly, then they should be able to recall and associate the logo with its referent. In the context of logo design for tourism purposes, recognition is defined as the degree to which people see the correspondence between the elements present in the design (and the logo as a whole) and the country's known or learned identity. Because national reputation circumscribes multiple factors, it is essential for a logo to capture the core characteristics of the country it represents. Recognition is enhanced when logos evoke established meanings or when they appear similar to other well-known symbols or objects.

Designing country logos, therefore, is a challenge partly due to the multi-faceted dimensions of national identity. It is also costly. Selecting an appropriate logo is a daunting task. As Colman et al. (1995) lament, "logotypes generate unique impressions, but the quality and type of these impressions are not always those intended by the designers" (p. 405). Many logos fall flat, failing to convey meaning through a hodgepodge of design elements that are irrelevant and do not connect to the market (Byrom and Lehman, 2007). Indeed, one of the nagging research gaps in destination branding is the effectiveness of brand slogans and logos (Pike et al., 2009). Pike et al. (2009) bemoan their observation that destination promotion has seen few creative ideas, and that most fail to achieve anything more than "ephemeral indifference" (p. 437).

Studies that examine audience reactions have identified the design characteristics of good logos (e.g., Henderson and Cote, 1998, van der Lans et al., 2009). The most common are simplicity (the ability to capture essence with a few design elements), naturalness (exhibited mainly through the use of commonly experienced objects), harmony (congruent patterns or arrangements of parts), proportion (the ratio of a logo's width to its height), and parallelism (the number of parallel lines in the design). Most of these are stylistic variables applied following some design convention.

\section{Gestalt Principles in Visual Design}

Behind these conventions, however, is a tacit recognition that visual perception is a "patternmaking process wherein people make sense of images through organization and meanings (recognition)" (Myers, 1990, p. 11). Gestalt principles of perception, proposed by German psychologists in the 1920s, describe the various ways people tend to visually assemble individual objects into groups or "unified wholes." In creating logos, it is important 
to consider the whole and not simply its parts because it is the complex totality of the elements in close relationship that ultimately creates meaning. This is made possible, according to Malamed (2009), because of the form-generating capability of our senses; where there is a collection of lines and curves, people see and recognize whole forms - the stronger the clarity of form, the more effective the design (Berryman, 1992).

Visual communicators do not agree on the exact number of gestalt principles that can be applied to design. Many, however, list six gestalt laws of perceptual organization particularly useful in the design of things-similarity, proximity, continuation, figure-ground relationships, closure, and assimilation (Read et al., 1997; Henderson et al., 2003; Cao, 2003; Lester, 2006; Myers, 1990). These have been shown to have a significant relationship with audience responses, including positive affect, perceptions of quality, recognition, and consensus in meaning (Henderson et al., 2003).

The principle of similarity states that design elements that are identical in terms of color, shape, size or orientation are grouped or seen together (Javier, 2011; Chang et al., 2001; Lester, 2006). Those that look the same unite, thus commanding attention (Fisher and SmithGratto, 1999). Proximity suggests that items are likely to be grouped together according to their nearness (Javier, 2011; Chang et al., 2002; Lester, 2006). Viewers assume that elements that are close to each other are related; those that are apart are not (Fulks, 1997). Continuation states that the eye is inclined to follow directions that are obvious or implied (Javier, 2011; Fultz, 1999). According to the figure-ground principle, the brain's continuous search for contours and edges forces it to distinguish between the foreground and background in a visual field (Fultz, 1999). Closure refers to the tendency to perceive multiple elements as a totality, to close gaps and to form wholes (Javier, 2011; Fultz, 1999). Assimilation is the process wherein a stimulus obtained by any one of the senses is related to the individual's vast storehouse of memory and experience. Also known as isomorphic correspondence, this phenomenon suggests that interpretations are derived from the viewer's experiences and knowledge. Thus, assimilation harkens to the ability of visuals to combine, compress and communicate social meaning, suggesting that people rely on the correspondence between the symbols in an image and what is known about the referent or the subject being represented in the visual. In the case of destination logos, the extent to which the symbolic elements are consistent with the known characteristics of a country is an important determinant of 
consumer evaluation (Chang et al., 2002). The more easily symbols are tied with the known aspects of a nation, the more readily it is perceived as a coherent unit in terms of the meanings it is designed to express.

Viewers take advantage of these principles to group elements together into organized wholes and to establish coherent relationships between and among them. Following gestalt arguments, after having recognized the individual elements of a whole, the viewer seeks a coherent interpretation of the total image. These principles have been shown to have a significant relationship with audience responses, including positive affect, perceptions of quality, recognition, and consensus in meaning (Henderson et al., 2003).

According to Masten (1988), people transfer sensations generated by visual elements such as logos to the product itself. When people rate the visual quality of logos as high, they assume that the products they represent are of high quality as well. Van den Bosch, Jong and Elving (2005) show empirical evidence demonstrating the relationship between corporate visual identity (logo, name, symbol, color, typography, and slogan) and corporate reputation dimensions (visibility, distinctiveness, authenticity, transparency, and consistency). Strong logos also can bolster people's evaluations of the countries they promote, considerably influencing purchasing, investing, residence, and travel decisions (Kotler and Gertner, 2002). In the same vein, logos of poor quality can damage a country's reputation.

Given the foregoing literature on the likely impact of gestalt principles as they are applied in the design of country logos for tourism, this study asks: Does the extent to which a logo demonstrate gestalt principles influence people's intention to visit the country being promoted? What is the influence of these principles on people's ability to recognize the country the logo represents?

\section{Method}

\section{Gestalt Traits}

A total of 154 logos were collected from the official government websites of 116 countries (some countries have more than one official logo). The logos were culled from the web portals of government agencies and/or instrumentalities responsible for the regulation of the tourism industry and the promotion of their respective countries as a tourist destination (e.g., 
the departments or ministries of tourism, commerce and trade, culture, natural resources and the environment).

Two graduate students in journalism and mass communication who have had intensive undergraduate and graduate courses in visual communication rated the extent to which six gestalt principles - similarity, proximity, continuity, figure-ground, closure, assimilationwere present in each $\log 0$ using a scale from 1 to 5 where " 1 " means low and " 5 " means high. The scores for each logo were averaged. To secure variance in logo quality, the two highest rated logos (Peru=20.8 and New Zealand=20.7) were considered images high in gestalt attributes. The scores were split at the median to identify the two logos that represent those that have medium-gestalt characteristics (Japan=13.7 and Tanzania=13.7). The two lowest scoring logos were designated as low-gestalt images (Aruba=8.3) and Bermuda 8.7). Table 1 shows the selected logos and their gestalt rankings.

Intercoder reliability was determined using Krippendorf's alpha $(\alpha)$. The results, shown in Table 2, indicate acceptable reliabilities.

Table 1. High-, medium-, and low-gestalt logos

\begin{tabular}{|c|c|c|}
\hline Gestalt level & Country logos & \\
\hline High & ú & NEW ZEALAND \\
\hline Medium & & The Land of Kilimanjaro \& Zanzibar \\
\hline Low & ARUBA & $\frac{\text { B E R M U D A }}{\text { feel the love. }}$ \\
\hline
\end{tabular}


Table 2. Intercoder reliability results

\begin{tabular}{|l|c|}
\hline Gestalt principle & Intercoder reliability (\%) \\
\hline Similarity & 78.4 \\
\hline Proximity & 74.1 \\
\hline Continuity & 71.8 \\
\hline Figure-Ground & 71.1 \\
\hline Closure & 79.2 \\
\hline Assimilation & 71.2 \\
\hline
\end{tabular}

\section{Recognition and Intention to Visit}

An online survey was conducted to examine the influence of tourism logos, categorized based on the presence of gestalt traits, on people's evaluations of a country and their intention to visit the country. The email addresses of 4,000 undergraduate students at a large university in the Midwest were randomly drawn from the university's official registration records. An invitation email was sent to the entire sample, inviting them to participate, and specifying a link to the online questionnaire. Three reminder invitations were sent weekly after the initial invitation. Those who chose to participate were asked to assess the six logos with three levels of gestalt traits.

The dependent variables in this study are recognition and intention to visit. Intention to visit a country was measured using a five-point Likert scale ( $1=$ strongly disagree, $5=$ strongly agree) in response to the statement "I would like to visit this country some day." Recognition refers to the extent to which respondents can match the logo with the country being depicted. This variable was measured by respondents' answers to two items: (1) I can identify this logo with the country it represents; and (2) This logo captures the characteristics of the country it represents (Cronbach's $\alpha=0.762$ ) also using five-point Likert scales ( $1=$ strongly disagree, $5=$ strongly agree).

Demographic information (age, gender, nationality, and frequency of visiting other countries) was also solicited. 


\section{Results}

A total of 208 graduate and undergraduate students 18 to 25 years old participated in the study of which $146(70.2 \%)$ were female.

To what extent did the logos capture the essence of the country they represent? In terms of eliciting recognition, logos with medium-gestalt characteristics $(\mathrm{M}=7.54, \quad \mathrm{SD}=1.81)$ outperformed the logos with high $(\mathrm{M}=6.72, \mathrm{SD}=1.89)$ and low gestalt levels $(\mathrm{M}=5.95$, $\mathrm{SD}=2.23$ ). The results of an ANOVA test indicate that recognition of the country varied by

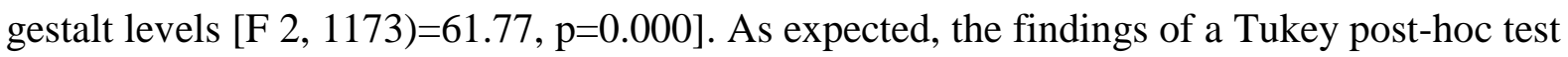
suggest that high-gestalt logos were perceived to be more effective in capturing the characteristics of the countries they represent than their counterparts with low-gestalt traits. Symbols with medium-gestalt characteristics also were significantly better at performing this function than logos rated low in gestalt attributes. However, those with high- and mediumgestalt characteristics did not differ in their ability to enhance recognition.

The higher recognition that went with medium-gestalt logos may be explained by the very descriptive nature of the symbols in this category. Japan's icon may look abstract, but is compensated by the popularity of the country and the well-known colors of its brand among American audiences. Tanzania's symbol can be considered the complete logo, brandishing the country's name, a slogan and a picture-book rendition of wildlife against the backdrop of Mount Kilimanjaro. These images are readily associated with safari and other adventurers one can expect in the African continent.

Logos high in gestalt traits registered the highest intention to visit among the respondents $(\mathrm{M}$ $=3.80, \mathrm{SD}=.874)$. The results of a one-way ANOVA suggest that the three gestalt levels evoked significantly different levels of intention to visit $[F(2,1179)=8.775, p=0.000]$. The findings of a Tukey post-hoc test show that high-gestalt logos produced significantly higher behavioral intention responses than logos that were low in gestalt characteristics $(M=3.60$, $\mathrm{SD}=1.01)$ and those that display medium-gestalt traits $(\mathrm{M}=3.52, \mathrm{SD}=1.011)$. Intention to visit did not differ significantly between the low- and medium-gestalt logos although in absolute terms, those rated low in gestalt or grouping attributes elicited a higher intention to visit among the student-respondents than logos in the medium-gestalt category. 
The higher behavioral attention elicited by the low-gestalt logos against their medium-gestalt counterparts ran counter to expectations. This may be attributable to the simple but easily understood symbols often found in low-gestalt logos. In open-ended evaluations, some respondents' volunteer that the Aruba icon, adorned by nothing more than three water droplets, is "an understatement" and "an exercise in simplicity." Many saw the Bermuda logo, which shows a pink pair of shorts seemingly hanging in mid-air and exhorting viewers in its slogan to "feel the love," as "not too attractive, but needs no further explanation."

\section{Discussion and Conclusions}

Quite often, decisions regarding logo design and selection are the exclusive purview of executives who apply subjective criteria and judgments (Masten, 1988). Because the deployment and promotion of visual identity is a significant public relations activity, the absence of systematic audience testing can readily put client countries at risk. In the context of country tourism promotion, this study aims to provide audience-centered empirical evidence for the logo characteristics likely to elicit the desired positive response. The main findings of this study have several theoretical and practical implications.

First, echoing the results of previous studies, the current study found that logos high in gestalt attributes indeed influenced the ease with which people can recognize the nations the logos stand for. The results are consistent with those of Chang et al. (2002) who observed that deploying gestalt principles in the design of corporate identity improves the evaluation of the products that carry these logos. This may be because, as Todorovic (2008) posits, "it is explains, "not attention that creates the forms, but rather the forms, organized in accord with gestalt principles, that draw attention" (p. 5345). The results buttress the notion that obvious Gestalt patterns can elicit positive reactions from target viewers. The findings also support the observation that the joint effect of gestalt grouping principles demonstrates "reasonable strength" (Kubovy and van den Berg, 2008).

Second, the findings add evidence in support of the notion that logos strong in patternmaking or grouping of elements have a higher propensity to enhance consumers' intention to visit these countries. 
Third, some results appear counter-intuitive. Although there was no statistically significant difference between high- and medium-gestalt in terms of recognition, the medium category was rated higher on this aspect. This suggests a preference for logos that are not simplistic but not overly complex that audiences lose touch of the main selling points. Although not statistically different, low-gestalt logos scored higher than medium-gestalt symbols on intention to visit. This indicates the enduring strength of simplicity in logo design.

This study has several limitations. First, only six country logos were subjected to the respondents' evaluation. Future studies that examine a wider array of logos may produce more generalizable results. Second, the degree to which these six logos represent high, medium or low gestalt characteristics may also be in question considering the ratings of only two design experts. Third, the study did not take into account the potential influence of preexisting knowledge about and attitude toward the object country. Because country image results from how people evaluate a country over time as a consequence of past and current developments and events, pre-existing knowledge and attitudes are moving targets that will always pose a challenge to the visual dimension of tourism promotion programs. Fourth, although the study followed the measures employed in previous studies, a single item used to measure the dependent variable intention to visit is vulnerable to reliability risk. Lastly, the sample demographics of this study were quite homogeneous in terms of nationality, age, and foreign travel experience. Future studies should test the same research questions on a more diverse population. 


\section{References}

Aronczyk, M. (2008). Living the brand: Nationality, globality and the identity strategies of nation branding consultants. International Journal of Communication, 2, 41-65.

Berry, N.C. (1989). Revitalizing brands. Journal of Consumer Marketing, 5(3), 15-20.

Berryman, G. (1992). Gestalt. In Notes on graphic design and visual communication (pp. 89). Los Altos, CA: Axzo Press.

Blain, C., Levy, S.E., \& Ritchie, J.R. (2005). Destination branding: Insights and practices from destination management organizations. Journal of Travel Research, 43, 328338.

Bowman, K. (2010). Sustainable tourism certification and state capacity: Keep it local, simple, and fuzzy. International Journal of Culture, Tourism, and Hospitality Research, 5(3), 269-281.

Byrom, J.W., \& Lehman, K.F. (2007, June). Corporate visual identity in local government: The role of the logo. In Proceedings of the 6th International Congress on Public and Non-profit Marketing (pp. 1-13), Portugal.

Cao, F. (2003). Application of gestalt principles to the detection of good continuations and corners in image level lines. Computing and Visualization in Science, 7, 3-13.

Colman, A. M., Wober, J. M., \& Norris, C. E. (1995). Sight bites: A study of viewers' impressions of corporate logos in the communications industry. Journal of the Market Research Society, 37(4), 405-415.

Chang, D., Dooley, L., \& Tuovinen, J. (2001, July-August). Gestalt theory in visual screen design - A new look at an old subject. Paper presented at the Seventh World Conference on Computers in Education, Copenhagen.

Cohen, D. (1986). Trademark strategy. Journal of Marketing, 50, 61-74.

Echtner, C. M., \& Brent Ritchie, J. M. (1991). The meaning and measurement of destination image. Journal of Tourism Studies, 2(2), 2-12.

Edell, J. A., \& Staelin, R. (1983). The information processing of pictures in print advertisements. Journal of Consumer Research, 10, 45-61.

Fang, X., \& Mowen, J. C. (2005). Exploring factors influencing logo effectiveness: An experimental inquiry (extended abstract). Advances in Consumer Research, 32, 161.

Fetscherin, M. (2010). The determinants and measurement of a country brand: The country brand strength index. International Marketing Review, 27(4), 466-479. 
Fisher, M., \& Smith-Gratto, K. (1999). Gestalt theory: A foundation for instructional screen design. Journal of Educational Technology Systems, 27(4), 361-371.

Fulks, M. (1997). Gestalt theory and photographic composition. Retrieved from www.apogeephoto.com/mag1-6/mag2-3mf.shtml.

Fultz, J. (1999). Theory of gestalt psychology. Retrieved from http://users.anderson. edu/ jfultz/gestalt.html.

Goodman, A. (2011, January 17). 2010 a strong year for global tourism, U.N. agency says. Retrieved from http://articles.cnn.com/2011-01-17/travel/tourism_Rebound _1_tourist-arrivals-unwto-international-tourism?_s=PM:TRAVEL.

Ha, T. (2012, Feb. 14). New tourism logo is criticized to be unintelligible. Retrieved from http://english.vietnamnet.vn/en/travel/18817/new-tourism-logo-is-criticized-to-beunintelligible.html.

Harish, R. (2010). Brand architecture in tourism branding: The way forward for India. Journal of Indian Business Research, 2(3), 153-165.

Henderson, P. W., \& Cote, J. A. (1998). Guidelines for selecting or modifying logos. Journal of Marketing, 62,14-30.

Henderson, P. W., Cote, J. A., Leong, S. M., \& Schmitt, B. (2003). Building strong brands in Asia: Selecting the visual components of image to maximize brand strength. International Journal of Research in Marketing, 20, 297-313.

Hutton, J. (1997). The influence of brand and corporate identity on consumer behavior: A conceptual framework. Journal of Brand Management, 5, 428-439.

Jaffe, E., \& Nebenzahl, D. (2001). National image and competitive advantage: The theory and practice of country-of-origin effect. Copenhagen: Copenhagen Business School Press.

Javier, L. (2011). Gestalt theory + visual metaphor = logo design. Retrieved from http://issuu.com/elaiyuarai/docs/gestalt.

Kleppe, I., \& Mossberg, L. (2006). Company versus country branding: Same, same, but different. In F. Asche (Ed.), Primary industries facing global markets: The supply chains and markets for Norwegian food and forest products (pp. 217-246). Copenhagen, Denmark: Copenhagen Business School Press.

Kotler, P., \& Gertner, D. (2002). Country as brand, product, and beyond: A place marketing and brand management perspective. Brand Management, 9, 249-261. 
Kubovy, M., \& van den Berg, M. (2008). The whole is equal to the sum of its parts: A probabilistic model of grouping by proximity and similarity in regular patterns. Psychological Review, 115(1), 131-154.

Lee, G., O’Leary, J. T., \& Hong, G. S. (2002). Visiting propensity predicted by destination image: German long-haul pleasure travelers to the U.S. International Journal of Hospitality \& Tourism Administration, 3(2), 63-92.

Lentschner, K. (2001, March 19). Behind the wave of corporate rebranding. Christian Science Monitor, 16-18.

Lester, P. M. (2006). The sensual and perceptual theories of visual communication. In Visual communication: Images with messages, $4^{\text {th }}$ ed. (pp. 50-64). Belmont, CA: Thomson Wadsworth.

Malamed, C. (2009). Gestalt your graphics: Improving instructional graphics. Retrieved from http://www.learningsolutionsmag.com/articles/157/.

Morrow, D. J. (1992). An image makeover. International Business, 5(3), 66-68.

Myers, J. (1990). The nature of perception. In The language of the visual art: Perception as a basis for design (pp. 9-20). Fort Worth, TX: Holt, Rinehart, and Winston.

Papp-Váry, A. (2010, June). Country slogans and logos: Findings of a benchmarking study. Paper presented at the 8th International Conference on Management, Enterprise and Benchmarking, Budapest, Hungary.

Pike, S., Bianchi, C., Kerr, G., \& Patti, C. (2010). Consumer-based brand equity for Australia as a long-haul tourism destinationin an emerging market. International Marketing Review, 27(4), 434-449.

Pimentel, R. W. (1997). Consumer preference for logo designs: Visual design and meaning. (Unpublished doctoral dissertation). University of Arizona, Tucson, AZ.

Rafaeli, A., Sagy, Y., \& Derfler-Rozin, R. (2008). Logos and initial compliance: A strong case of mindless trust. Organization Science, 19(6), 845-859.

Read, S., Vanman, E. J., \& Miller, L. C. (1997). Connectionism, parallel constraint satisfaction processes, and gestalt principles: (Re)Introducing cognitive dynamics to social psychology. Personality and Social Psychology Review, 1(1), 26-53.

Robertson, K. R. (1989). Strategically desirable brand name characteristics. Journal of Consumer Marketing, 6, 61-71. 
Roe, D., Ashley, C., Page, S., \& Meyer, D. (2004). Tourism and the poor: Analysing and interpreting tourism statistics from a poverty perspective. Working Paper No. 16. Retrieved from http://www.propoortourism.org.uk/16_stats.pdf.

Todorovic, D. (2008). Gestalt principles. Scholarpedia, 3(12), 534. Retrieved from http://www.scholarpedia.org/article/Gestalt_principles.

Travel Blackboard (Asia Edition). (2012, February 16). Vietnam's ‘timeless charm' faces testing times. Retrieved from http://www.etravelblackboardasia.com/article/81728/ vietnams-timeless-charm-faces-testing-times.

United Nations World Tourism Organization (UNWTO). (2011). International tourists to hit 1.8 billion by 2030 . Retrieved from http://media.unwto.org/en/press-release/

2011-10-11/international-tourists-hit-18-billion-2030.

van den Bosch, A. L. M, de Jong, M., \& Elving, W. J. L. (2006). Managing corporate visual identity: Exploring the differences between manufacturing and service, and profitmaking and nonprofit organizations. Journal of Business Communication, 43, 138157

van der Lans, R., Cote, J. A., Cole, C. A., Leong, S. M., Smidts, A., Henderson, P. W., Bluemelhuber, C., Bottomley, P. A., Doyle, J. R., Fedorikhin, A., Moorthy, J., Ramaseshan, B., \& Schmitt, B. H. (2009). Cross-national logo evaluation analysis: An individual-level approach. Marketing Science, 28(5), 968-985.

Vietnam National Administration of Tourism (VNAT). (2012). New logo-slogan. Retrieved from http://www.vietnamtourism.gov.vn/english/index.php?cat=0125.

Wanderlust Travel and Destination Marketing. (2009). Logo design for travel and destinations. Retrieved from http://www.createwanderlust.com/logo-design-fortravel-and-destination-brands.

Wheller, A. (2006). Designing brand identity. Hoboken, NJ: John Wiley \& Sons.

Zhang, Y., Feick, L., \& Pike, L. (2006). The impact of self-construal on aesthetic preference for angular versus rounded shapes. Personality and Social Psychology Bulletin, 32(6), 794-805. 